\title{
Management of chronic obstructive pulmonary disease exacerbations: How well are we doing?
}

\author{
Nicholas T Vozoris MHSc MD FRCPC
}

$\mathrm{C}$ hronic obstructive pulmonary disease (COPD) affects a significant proportion of the general Canadian population, with recent population-based prevalence estimates ranging from approximately $4 \%$ to $10 \%(1-3)$. COPD is commonly characterized by acute exacerbations, sustained worsenings of respiratory symptoms leading to an increase in the use of maintenance medications and/or supplementation with additional medications (4). Although highly variable, the average COPD patient with moderate-to-severe airflow reduction experiences two to three exacerbations per year (5). COPD exacerbations requiring hospitalization are associated with increased mortality (6). Prompt and appropriate treatment of exacerbations can improve quality of life and lower hospitalization risk (7). There are relatively few studies examining the quality of medical care COPD patients receive during acute exacerbations (8-9). These studies have often focused only on pharmacotherapy management and have revealed suboptimal care such as reduced systemic corticosteroid and antibiotic prescription (8-9).

In the current issue of the Canadian Respiratory Journal, Sandu et al (10) (pages 175-179) undertook a fairly comprehensive examination of acute COPD exacerbation management among patients with established COPD before, during and following hospital admission, compared care given among different physician groups (ie, respirologists, general internists, hospitalists), and reported some startling and concerning results. Before presenting to hospital, less than one-half of COPD patients were receiving a combination long-acting beta-agonist/ inhaled corticosteroid or a long-acting anticholinergic, and a small minority had seen a respirologist. Very small proportions had been prescribed any outpatient antibiotics or systemic corticosteroids. During hospital admission, only approximately one-half of COPD patients received the triad of bronchodilators, systemic corticosteroids and antibiotics; $42 \%$ did not receive systemic corticosteroids; and 16\% did not receive antibiotics. Arterial blood gas measurement and spirometry performance were also low. On hospital discharge, only about one-quarter of COPD patients were sent home on a combination longacting beta-agonist/inhaled corticosteroid and a long-acting anticholinergic. While COPD care appeared to be suboptimal among all physician groups examined, care appeared to be relatively poorer among general internists and hospitalists compared with respirologists, and the former two physician groups had abysmally poorer use of preprinted orders despite their availability.

Several factors should be considered when interpreting these study results. First, this study examined COPD patients presenting to only one hospital in one Canadian city and, therefore, results may not be generalizable to other Canadian centres. Second, certain aspects of care that were found to be reduced, such as receipt of arterial blood gase measurements, spirometry and antibiotics, may not have been indicated in some patients. Canadian Thoracic Society (CTS) COPD guidelines (4) recommend performing arterial blood gas measurements only if there is evidence of hypoxemia by oximetry, and both CTS (4) and Global initiative for chronic Obstructive Lung Disease (GOLD)
(11) guidelines recommend against performing spirometry during an exacerbation because of poor correlation between lung function decline and exacerbation severity according to symptoms (5). The CTS (4) and GOLD (11) guidelines also only recommend antibiotic therapy for exacerbations requiring mechanical ventilation or for purulent exacerbations because recovery can usually occur without antibiotics in individuals producing mucoid phlegm during an exacerbation (12). Third, while 'triple therapy' with a combination longacting beta-agonist/inhaled corticosteroid and a long-acting anticholinergic has been shown to reduce COPD exacerbation-related hospitalization risk (but not the overall risk of COPD exacerbation) (13), this was reported only among a specific group of COPD patients: those with forced expiratory volume in $1 \mathrm{~s}\left(\mathrm{FEV}_{1}\right)<65 \%$ predicted plus a history of at least one acute COPD exacerbation. Because Sandu et al (10) collected no information on lung function in study participants, it is premature to conclude, based on existing evidence, that all of the COPD patients who were discharged from hospital without 'triple therapy' received suboptimal care because some may have had a baseline $\mathrm{FEV}_{1}>65 \%$. Fourth, while care appeared to be more suboptimal among general internists and hospitalists than respirologists, the observed discrepancy may, in part, be explained by certain legitimate factors. Compared with the respirologists, COPD patients admitted under the care of the general internists and hospitalists were older and a greater proportion had multiple comorbidities. Prescription of some types of COPD pharmacotherapy, such as systemic corticosteroids and long-acting anticholinergics, may have been reasonably limited by general internists and hospitalists given the concern for possible drug side effects because of patients' older age and greater comorbidity. COPD patients admitted under the care of the general internists and hospitalists versus respirologists may have also experienced less severe exacerbations, as evidenced by their significantly lower respiratory rates, higher oximetry levels, lower $\mathrm{PaCO}_{2}$ levels and higher $\mathrm{pH}$ levels. A possible lesser degree of COPD exacerbation severity among the former groups' patients may have again reasonably limited the prescription of some types of COPD pharmacotherapy. Finally, although management of acute COPD exacerbation was more suboptimal among general internists and hospitalists versus respirologists, curiously, this did not translate into significant differences in relapse or mortality rates among the three groups. The study may have been underpowered to detect potentially significant differences in these outcomes.

Although these limitations should be considered when interpreting the study results, Sandu et al (10) are highlighting a very likely real, underappreciated and important problem in the care of Canadian COPD patients: physician management of acute COPD exacerbations is suboptimal, especially among nonrespirologists. Moreover, suboptimal COPD exacerbation management appears to occur at multiple time points (before, during and after hospital admission) and extends beyond the sphere of pharmacotherapy to involve other critical aspects of care such as identification of hypercapnea and assessment of

Division of Respirology, Department of Medicine, St Michael's Hospital, University of Toronto, Toronto; Division of Internal Medicine,

Department of Medicine, Kingston General Hospital, Queen's University, Kingston, Ontario

Correspondence: Dr Nicholas T Vozoris, Division of Respirology, Department of Medicine, St Michael's Hospital, 30 Bond Street, Toronto,

Ontario M5B 1W8. Telephone 416-864-6026, fax 416-864-5649, e-mail nick.vozoris@utoronto.ca 
home oxygen needs. We, as respirologists, likely need to do a better job of implementing our own COPD management guidelines. More and better COPD education is also likely needed among nonrespirologist physicians and nonphysician health care professionals. Sandu et al (10) are likely correct that availability and implementation of

\section{REFERENCES}

1. Vozoris NT, Stanbrook MB. Smoking prevalence, behaviours, and cessation among individuals with COPD or asthma. Respir Med 2011;105:477-84.

2. Buist AS, McBurnie MA, Vollmer WM, et al. International variation in the prevalence of COPD (the BOLD Study):

A population-based prevalence study. Lancet 2007;370:741-50.

3. Gershon AS, Wang C, Wilton AS, Raut R, To T. Trends in chronic obstructive pulmonary disease prevalence, incidence, and mortality in Ontario, Canada, 1996 to 2007: A population-based study. Arch Intern Med 2010;170:560-5.

4. O'Donnell DE, Aaron S, Bourbeau J, et al. Canadian Thoracic Society recommendations for management of chronic obstructive pulmonary disease - 2003. Can Respir J 2003;10(Suppl A):11A-65A.

5. Seemungal TA, Donaldson GC, Bhowmik A, Jeffries DJ, Wedzicha JA. Time course and recovery of exacerbations in patients with chronic obstructive pulmonary disease. Am J Respir Crit Care Med 2000;161:1608-13.

6. Connors AF, Dawson NV, Thomas C, et al. Outcomes following acute exacerbation of severe chronic obstructive lung disease. The SUPPORT investigators (Study to Understand Prognoses and Preferences for Outcomes and Risks of Treatments). Am J Respir Crit Care Med 1996;154:959-67.

7. Wilkinson TM, Donaldson DC, Hurst JR, Seemungal TA, Wedzicha JA. Early therapy improves outcomes of exacerbations of chronic obstructive pulmonary disease. Am J Respir Crit Care Med 2004:169:1298-303. pre-printed orders for acute COPD exacerbations may represent one simple and effective way of improving care, at least during the hospital admission stage. Given the frequency with which exacerbations occur in the COPD population and their profound clinical consequences on patients, we simply must do a better job.

8. Rowe BH, Cydulka RK, Tsai CL, Clark S, Sinclair D, Camargo CA Jr. Comparison of Canadian versus United States emergency department visits for chronic obstructive pulmonary disease exacerbation. Can Respir J 2008;15:295-301.

9. Lodewijckx C, Sermeus W, Vanhaecht K, et al. Inhospital management of COPD exacerbations: A systematic review of the literature with regard to adherence to international guidelines. J Eval Clin Pract 2009;15:1101-10.

10. Sandu SK, Chu J, Yurkovich M, Harriman D, Taraboanta C, FitzGerald JM. Variations in the management of acute exacerbations of chronic obstructive pulmonary disease. Can Respir J 2013;20:175-9.

11. Global Initiative for Chronic Obstructive Lung Disease (GOLD). Global Strategy for the Diagnosis, Management, and Prevention of Chronic Obstructive Pulmonary Disease. Updated 2013. <www.goldcopd.org/uploads/users/files/GOLD_Report_2013_Feb20. pdf $>$ (Accessed March 2013).

12. Stockley RA, O'Brien C, Pye A, Hill SL. Relationship of sputum color to nature and outpatient management of acute exacerbations of COPD. Chest 2000;117:1638-45.

13. Aaron SD, Vandemheen KL, Fergusson D, et al. Tiotropium in combination with placebo, salmeterol, or fluticasone-salmeterol for treatment of chronic obstructive pulmonary disease: A randomized trial. Ann Intern Med 2007;146:545-55. 


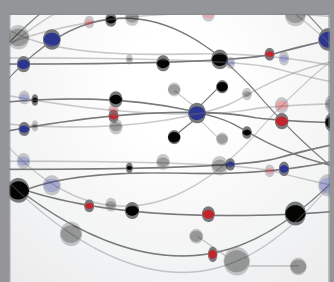

The Scientific World Journal
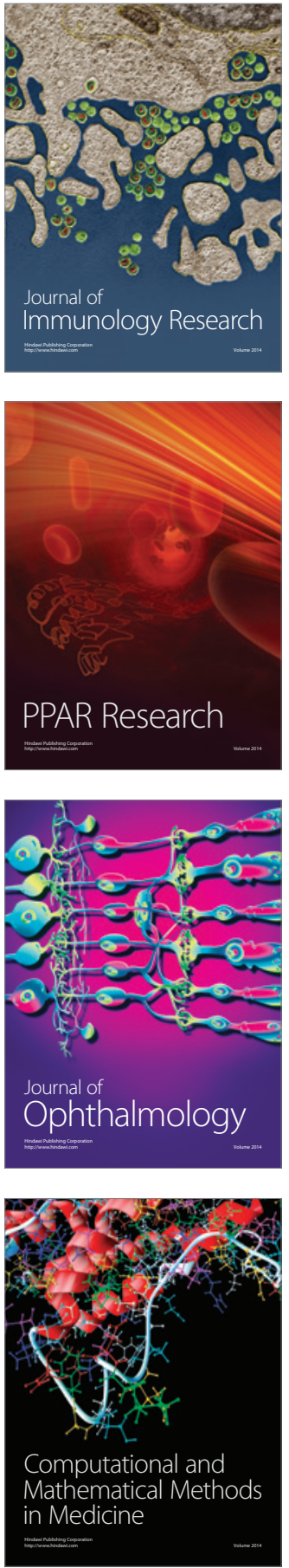

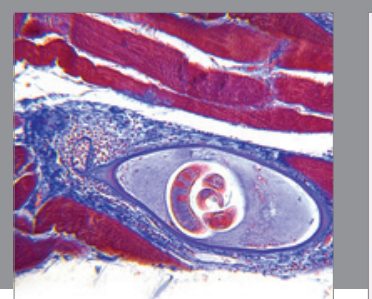

Gastroenterology Research and Practice

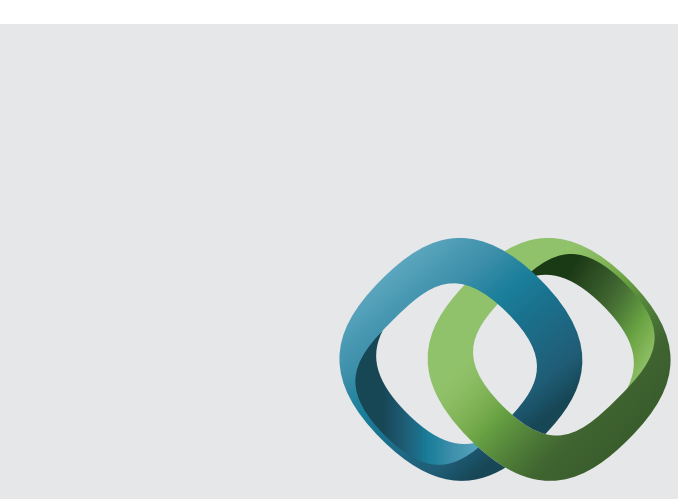

\section{Hindawi}

Submit your manuscripts at

http://www.hindawi.com
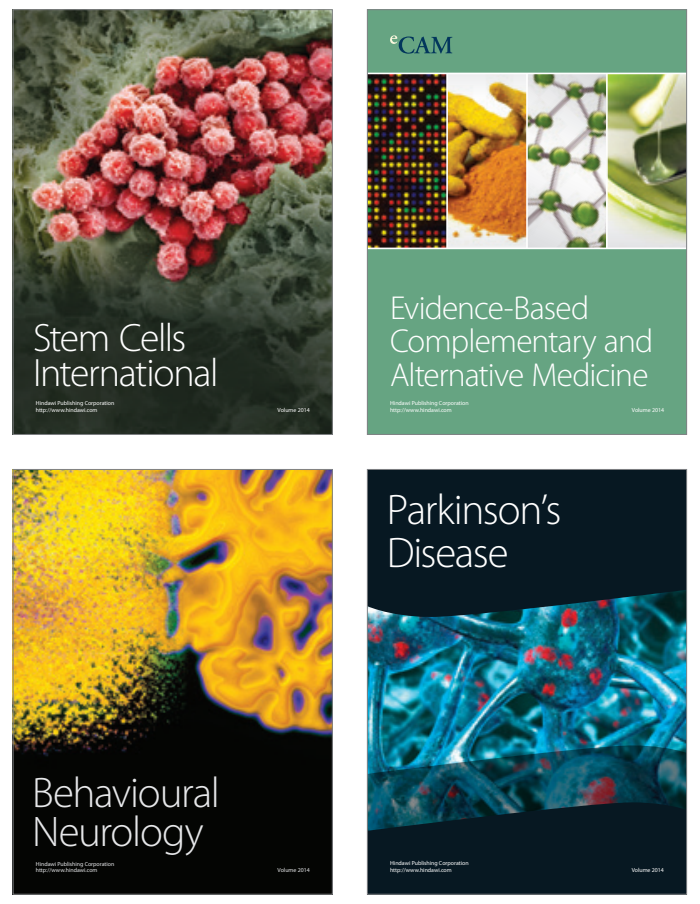
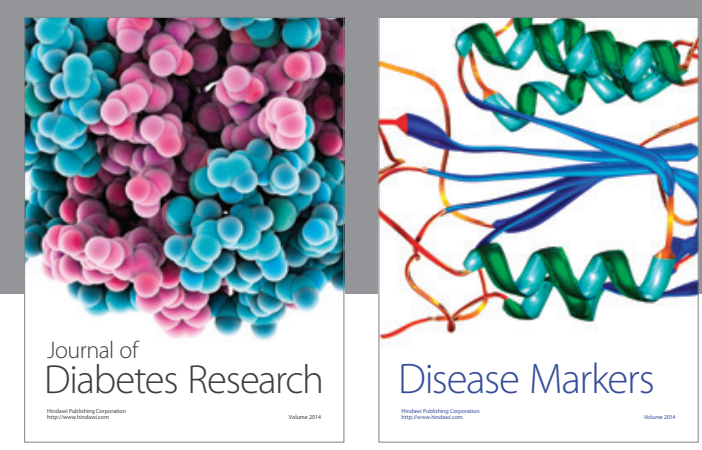

Disease Markers
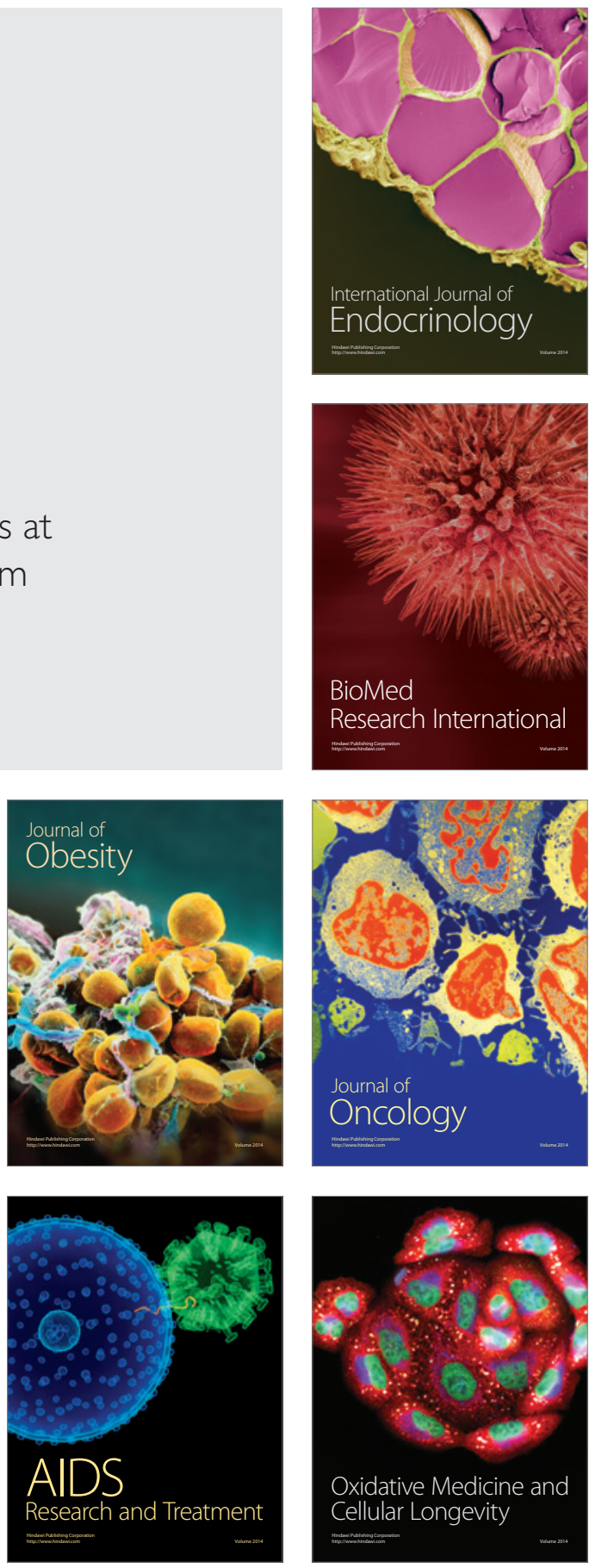